\title{
PHILOSOPHY OF POSTMODERNISM AS A THEORETICAL JUSTIFICATION OF THE WOMEN SOCIAL VALUE
}

\author{
Eleonora Skiba \\ Doctor of Philosophical Science, Associate Professor, Professor at the Department \\ of Social and Humanities, Dnipropetrovsk State University of Internal Affairs, Ukraine \\ e-mail: eleonora.skiba@gmail.com,orcid.org/0000-0002-6364-5207
}

\section{Summary}

The study analyzes postmodern discourse and its connection with feminist, gender studies and the philosophy of postmodernism. The analysis proves that gender theory shares with postmodernism methods of explanation and interpretation of human experience such as reconstruction, hermeneutics and others. The constructivist methodology of culture reading allowed us to argue that socio-cultural inequality and the exclusion of women from the general picture of the world as an active subject has no natural basis, but arises as a result of socio-cultural marginalization of women. The study examines the philosophical aspects of gender discourse and their interpretation in postmodernism. The work characterizes gender discourse in the context of postmodern philosophy, the philosophical foundations of gender theory and the main aspects of the interaction of postmodern philosophy and gender theory. Historical and philosophical analysis of the formation of gender theory and its relationship to the philosophy of postmodernism show that there is much in common between gender theory and postmodernism. Both the theory of postmodernism and gender theory argue that the metanarratives of the Enlightenment lost their legitimizing force, that the demands and claims that were presented as universal were valid only for men and women of a certain culture, class and race and a certain historical period.

Keywords: patriarchy, postmodern turn, feminism, gender theory, subordinate position of personality, socio-cultural marginalization of women.

\section{DOI: https://doi.org/10.23856/3838}

\section{Introduction}

Modern ideas about the future of culture and society, in general, are inextricably linked with the need for maximum personal development of both men and women. One of the effective tools for achieving the goal of creating a just and harmonious society is the inclusion of gender research in the system of modern philosophical knowledge, which requires identifying the origins of this field of knowledge.

The purpose of the study is to reveal and subject to socio-philosophical analysis the content and role of gender research in postmodern culture, to identify trends in their development and interaction with the philosophical works of postmodernism. To achieve this goal, we solved such tasks as the study the philosophical and methodological interaction of gender theory and postmodernism in Western European philosophy, and establishing the essence of gender theory, the reasons for its emergence in the system of modern humanities.

The methodological basis of scientific research is characterized by a complex unity of hermeneutic, phenomenological, concrete-historical methods, the method of comparative analysis using various techniques based on the principles of methodological pluralism, which take into account the peculiarities of the dialectical method. 
The problem of person both men and women, which took shape in the concepts of the crisis of philosophy in the second half of the 20th century, is, as we know, a multifaceted phenomenon and extremely important for a number of humanitarian sciences. The ensuing postmodern turn of philosophical thought raised problems that covered almost all areas of philosophical "discourse about person." This postmodern philosophical discourse, which was formed on the theoretical level primarily in the works of T. Adorno, M. Horkheimer, M. Foucault, J. Deleuze, J.-F. Lyotard, J. Derrida and others, entered into interaction with gender attitudes of the vision of the world by men and women, their identification, methods of cognition, problems of power and domination in the practical life. The connection of postmodern discourse with gender research, feminist philosophy in general, is a relevant and significant philosophical problem that covers both various areas of human activity and different approaches to scientific interpretation of their relationship, interaction. When developing on the academic basis of the last third of the XX century, gender theory is not separated from postmodernism. Postmodernism and gender theory are considered by scholars as the two most important cultural and political currents of the last decades of the last century. They are united by a deep critique of traditional philosophy. Despite a number of important features of feminist philosophy, the scientific consideration of gender theory is impossible without postmodern texts, without analyzing their relationship and differences, because although both gender theory and postmodernism have offered a deep critique of the institutions of philosophy, they evolved from opposite social and philosophical problems. Postmodernists began with developing a metaphilosophical perspective, but in gender studies philosophical issues are usually inextricably linked to social critique of the subordinate position of women in patriarchal culture. Feminist theory of the late 70's-80's worked out the foundations of gender research and paved the way for solving problems that are now defined as gender issues. Issues of the definition and nature of postmodernism as an outstanding phenomenon of the West at the end of the 20th century are the subjects of scientific debates not only by philosophers, but also by sociologists, literary critics, and political scientists. The range of assessments, which reflect the attitude towards this complex phenomenon, is very wide - from sharply negative to laudatory, but, as it seems to us, this cultural phenomenon gave the development to new directions in the humanities and therefore deserves the attention of researchers.

\section{Formation of a New Philosophical Paradigm}

When basing on the assertion that any theorizing should proceed from the purpose of the research, the focus of our scientific attention will be on those significant problems of postmodernism, which partially coincide or run parallel with the theory of gender and the practice of postmodern politics.

The theory of postmodernism, its flexible conceptual structure both constitutes and reflects postmodern culture with all its discourses. In this culture, gender discourse plays, according to scientists, far from the last role. The term itself indicates that the new postmodern culture in many of its forms and aspects continues and completes the traditions of modernism.

As we know, one of the most famous definitions of postmodernism belongs to J. Baudrillard, for who postmodernity is a characteristic of the universe, where clear definitions are impossible. Only the game of definitions takes place. The limit of possibilities has been reached. Self-destruction has occurred. The entire universe has deconstructed. All that's left for us is to play with the pieces of universe. Play with parts is postmodernity (Kellner, 1990). For Giddens' the late modernity, it is a term he prefers, is a time when we are becoming more and more cut off from social relations. This is a period of increasing risk for all members of society, mainly 
because old truths are not perceived as such ones. This is a time of increasing self-reflection, when the very knowledge produced in the world helps to shape the appearance of this world (Giddens, 1991). We can add that this is the time when media images, modes of information, "modes of signification" and "aestheticization" of daily life became the wide spread feature of modern experience. We are living in the media and through the media. Postmodernism is the time of consumer culture, the time of new hyper technologies (Stone, 1996). W. Simon believes that the images associated with postmodernism are not just a subject of style, clichés or intellectual preferences, but an expression of such a profound change, "shift" that humanity has hardly experienced since the Renaissance. In many ways, these changes are even more profound, as they directly affect many more people and many more aspects of their lives than they affected in the Renaissance period. The "decentralization" that followed the Copernican revolution initially affected a few individuals. However, over time this has had an impact on many lives as a result of, for example, communication by satellite, and global access to the technologies of reception of this information in our time. As a result, these changes and the very experience of changes not only directly transformed our concepts of time and space, but also transfigured the very experience of time and space for millions of people (Simon, 1996).

Moreover, researchers talk about changes in human behavior and about "elasticity of identity", about transforming and have already transformed dimensions of subjectivity, about changed dimensions of what it means to be human. According to researchers, one of the most difficult aspects of discussing the social conditions and qualities of subjectivity of experience, which is important for understanding postmodernism, is the pluralism of meanings, derived from the pluralism of perspectives and "voices", and - more importantly - the pluralization and individuation of human experience.

Despite all its inconsistency and opacity the term "postmodernism" itself has been used extremely widely in the last quarter of a twentieth century - and not only in philosophy, but also in architecture, literature, painting, sculpture, aesthetics, linguistics, psychoanalysis, historiography, which allows scientists to talk about poetics of postmodernism. On the other hand, researchers argue that postmodernism cannot simply be used as a synonym for modernity. It is also not an international cultural phenomenon, being primarily a European and American phenomenon. As you know, the main debates about the theories that make up postmodernism are in the mainstream of the French philosophical school. Perhaps most cited is Jean-François Lyotard, whose book The Postmodern Condition: A Report on Knowledge (1979) is considered the most powerful theoretical expression of postmodernism. Lyotard calls to reject "grand narratives", as he names metanarratives, universal truths of Western culture. The faith in them has been lost. It is a kind of bright postmodernism idea of its contempt for authority in all its manifestations.

S. Sim, the author of well-known works on the philosophy of postmodernism, believes that one of the best ways to describe postmodernism would be skepticism - skepticism about authorities, acquired knowledge, cultural and political norms, - everything that represents a centuries-old the tradition of Western philosophical thought, rooted in classical Greek philosophy. Skepticism, the researcher notes, is basically a negative form of philosophy that undermines other philosophical theories that claim to possess the "ultimate truth" or the criteria for determining it. The term that Sim proposes to describe this style of philosophizing is "anti-fundamentalism". Anti-fundamentalists challenge the validity of the foundations of discourse by asking questions about what guarantees the validity of any grounds. It is noted that here an example for postmodernists in many respects was Nietzsche, whose call for a reassessment of all values was a kind of battle appeal for postmodernism (The Routledge Companion to Postmodernism, 2011). 
Although the philosophy of postmodernism is fundamentally diverse, scholars note some recurring features, such as skepticism, anti-fundamentalism, and an almost reflexive dislike of authority. All this gives the right to discuss postmodernism as a recognized direction of philosophy. Scholars argue that postmodernism is fundamentally contradictory, unquestionably historical, and inevitably political. Its contradictions may be the contradictions of late capitalism, but whatever their reason, they certainly manifest themselves in the important postmodern concept of the "presence of the past" (the name of the world famous art exhibition in Venice "Venice Biennale" in 1980, which gave institutional recognition postmodernism in art). Hence, according to L. Hutcheon, irony takes the dominant role in postmodernism (Hutcheon, 2003).

As it is controversial and working within the system, which it strives to overthrow, it is difficult to consider as a new paradigm. Scientists believe, when claiming that since postmodernism is not the new paradigmatic definition, it is not a logical concept that determines the real objects. At the same time, the heterogeneity of social experience, the pluralism of mirror reflections of the "ego", a significant expansion of the field of mental reality allow scientists to assert that the rejection of paradigmatic orders and the transition to post-paradigmatic conditions are the main characteristics of postmodernism.

Paradigmatic contexts, W. Simon notes, implement a high degree of consensual meanings, shared meanings that "fit" almost seamlessly as they are drawn from a small number of dominant paradigms, which in turn are considered to be some universal ultimate source of truth.

Thus, patriarchy, for example, as a cultural practice describes (and prescribes) patterns of behavior not only within the family, but also between the monarch and the subject, the employer and the worker, the healer and the patient, the priest and the parishioner, the teacher and the student. Even though individuals change roles, dominant cultural styles remain unchanged. As a result, the principle of hierarchy is viewed as natural and universal as the relationship between the individual and the Lord God, the Heavenly Father (Simon, 1996).

A post-paradigmatic context, the researcher continues, is the place where this seamless integration gradually disappears. When they are manifesting in multiple forms, devoid of absolute authority, even the most iconic aspects of social life become platforms for conflicting or alternative interests and options.

To a lesser extent, it is assumed that there is some commonality of shared meanings or common knowledge, especially when discussing what we are all participants in - human experience. Postmodernists are sure: the dream of the middle of the XX century about the realization of a systemically integrated science of man remains a dream, perhaps deceptive and deceiving, and, like all dreams, driven by desire rather than reality. Ernest Gellner writes in his work "Mind and Culture" that in a stable traditional world, people had identities associated with their shared vision of nature and society. Instability and rapid changes in both knowledge and society have deprived such individuals of their former sense of security. Identities are now more ironic and conventional than they ever were, or when they unjustifiably thought so (Gellner, 1992).

Scientists argue that it is the normalization of change that is becoming one of the critical aspects of postmodernism, and the unprecedented degree in which change truly permeates all aspects of our life. At the individual level, changes occur at ever shorter intervals, with the result that close groups share fewer and fewer "natural paradigms." In other words, the interaction of communities is constantly under threat as the ability to "share worlds" is taken for granted. This loss, as noted, engenders distrust in others, in self, etc. Even our conscious attempt to preserve the past experience causes, as noted, some a kind of nervousness, as if we expected to encounter those signs that proclaim that some part of our past is "closed for repair." As a result, stress levels are continuous, uneven in intensity. Often, our strategic responses to 
the stress of change are either adaptation to the demands of the present, which means the risk of alienation from who we were, or difficult, deliberate regulation of behaviors that were once unquestioned as our being in the world. For example, many people brought up in certain rules of gender behavior, in the new conditions of social values, must agree with radically changed rules (often at the cost of alienation from the old requirements of identity), or, on the contrary, resist these new values (at the cost of the risk of alienation from the "renewed" the world and yourself in it).

The dilemma of choice is characteristic of both women and men, for whom devotion to today's socio-cultural gender changes is a kind of betrayal of their former selves. Such internal conflicts often include problems of marriage, divorce, number of children, family and work obligations, career and others.

The next aspect of postmodernism is the extreme rise of individualization, which scholars describe as a consequence of the multiplicity and segregation of roles available to the individual, and often imposed on him. As a result, people can share nearly identical role portfolios without sharing the same commitments or, for example, the same background. More importantly, however, such people will have little reason to share a common collective identity (Simon, 1987: 60-89).

Of course, this does not mean that strong group identities do not exist at all, but critics emphasize that most of us experience these shared identities only partially and conditionally. The social landscape arises where the ego and its narratives of self-affirmation, self-sustaining, and self-development are spoken by an increasingly decentralized self, and this self is more than the sum of a portfolio of social roles.

There is an implicit shift from behavior that expresses feelings of "natural identity" to one that is described as "presented identity". As a result, the standardization or apparent uniformity of social life is hampering growing pluralism at the level of individual experience. The individual, to a greater extent, experiences postmodernity as an expansion and increase in choice, a choice that, nevertheless, is often irregular in its availability. Researchers assume that the "ego" is not presented as a ready-made construct within social life, but it manifests itself as a process, as a continuous production of social life, a production that must change even at its fundamental levels.

Since significant changes occur within a social group, W. Simon argues: the proliferation of choice should determine the qualitative growth of the internal dialogue of the "ego" and, thus, should also cause a shift in the policy of the "ego" (Simon and others, 1993: 411-426). The social roles we take are more and more experienced not as natural and fixed representations of the ego, but selective, like the costumes we wear from time to time, as statements who we are and whom we want to be. This broadened area of reflexive control, "management," is the main source of the development of a guiding and abstract self. While this implies a strong ego, it is not always and not necessary. Sometimes we are not the part of our passions but we are the observers of these conflicting forces. The real "ego" is the "I" who is watching over "me" and the one who is the scene of all these incidents, these conflicts.

\section{Gender Relations as a Form of Power}

In the early 1990s, gender analysis of society, important for the humanities as a whole, introduced the category of gender into the sphere of anthropophilosophical discourse. In this vein, researchers pay special attention to gender as a set of expectations and instructions, as an important hermeneutics of truly all social experience and all responses to this experience. 
To the extent that the gender system provides the basic structure within which the keys to identity are "sorted," the complexity of responses will be an ever-increasing by-product of modern Western experience.

In those situations that gender differences are mutually exclusive, individuals often have to choose between specific desires, which usually declare their presence by strict restrictions on gender differences, and the implications of the broader meaning of gender identity.

Scientists agree that the importance of gender in developing and maintaining self-identity has certainly increased in recent years, as gender remains one of the few remaining aspects of identity that really affects all aspects of our life.

It is necessary to note the importance of M. Foucault's ideas in postmodern theories, in general, and in theoretical models of gender, in particular. First of all, M. Foucault substantiated the high importance of gender in Western European culture, using concrete historical material to show how this importance was formed

Pointing to the special role of discursive practices, Foucault argues that their ultimate goal is the maximum possible control over the individual. M. Foucault connected the characteristics of discourse with the functions of power, introducing the concept of a system of exclusion and a system of control over the production of discourse. Paying attention to the most important role of ritual, Foucault argues that all concepts, including gender, appear before the individual not in a certain natural form, but as a result of discourse. He writes that the world is not an accomplice of our knowledge, and there is no any pre-discursive providence that would make it benevolent to us. Rather, discourse should be understood as the violence that we commit to things - at least - as a kind of practice that we impose on them; and it is within this practice that the events of discourse find the principle of their regularity (Foucault, 1996: 58-59).

Foucault showed that the gender of the individual over a long period of human history, especially from the middle of the 17th century, became an object of control and subordination. The verbalization of sex and related processes originates from the Christian principle of confession, which not only survived in modern times, but also developed into an out-of-church ritual of "exhaustive confession." According to Foucault, the emphasis on gender differences should also be considered as a form of manifestation of power, since the gender of an individual is one of the elements of power relations.

Control over any manifestations of gender is possible only with the help of the above-mentioned discursive practices as a way of interpreting certain gender problems, attributing social significance to them. The social institutions (school, law, church, medicine, art, etc.) of Western European society, Foucault believes, constantly reproduce their "truth" about the essence of sex. Consequently there is a fixation of all manifestations of gender and the ascription of normativity and evaluation of them.

We are sure that the definition is always essentialist's character, and therefore a norm is needed for power. Once a norm is created, its explanation organizes our understanding of all other variations and variations in the logic of the "normal". The power of the "norm" is manifested in its ability to establish a "difference" and "mask" this difference, turning it either into a variety or a deviation.

The pressure that creates the "tyranny of the norm" is obvious, and the reluctance to explain it is not a problem of theory or methodology. Rather, it is a problem of social life or a problem of social theory in social life (Simon, 1996).

Poststructuralism has a profound impact on what Western criticism calls "the feminism of difference." The most important argument for L. Irigaray, for example, is that gender identity, 
especially female, is not fixed, it is a fluid process that cannot be reduced to any essentialism or norm of behavior (in this case, patriarchy is an extracted norm of behavior).

Theorists, following L. Irigaray, use this form of argument to challenge patriarchy, especially assumptions about specifically masculine and feminine traits, leading to gender stereotypes and used to oppress women (Irigaray, 1977).

It should be noted again that, according to researchers, the quintessence of postmodernism is the most influential voice of J.-F. Lyotard. In his philosophy the criticism of anti-authoritarianism runs like a red thread. Lyotard's goal is to destroy the authoritarianism caused by metanarratives ("grand narratives"), which, he claims, suppress the creativity of the individual.

We should no longer rely on them, he says; we must not let them guide us in public or private life. There is no need to fight metanarratives. You just have to stop believing them, and they themselves will "fade" (Lyotard, 1984).

Perhaps this is a somewhat idealized vision of the political process, but commentators see the correctness of such a vision in the collapse of, for example, the socialist camp in Eastern Europe: people stopped believing in the dominant ideology, and it simply ceased to exert any influence on their will.

In many respects, the difficulties of gender thinking are due to the fact that gender, both as an analytical category and as a social process, is relative and consists of internally interdependent components. However, gender relations are considered by almost all researchers as a relationship of domination and power, which is hidden and disguised in many different ways, including the very possibility of the word "woman", its definition in terms of sex or "Other", which was impossible without Foucault's concepts of systems of exceptions and control of society over its individual representatives.

Gender researchers show that the traditional order is more likely to be destroyed in highly differentiated societies, forming extremely diverse and situational. It, on the one hand, increases the possibility of contradictions within the framework of predominant gender logic and, on the other, offers multiple grounds for collective action, the theoretical basis of which in most cases are the analyzed works of postmodern philosophers.

Significant changes in the field of gender relations of modern Western society and postmodern culture undoubtedly took the form of constant and open egalitarian processes. Gender theory, which is an integral part of the philosophical discourse of postmodernism, directly affects how these processes take place not only in the socio-political sphere of European countries, but also in ethics, aesthetics, religion, natural sciences. It is in the direction of fundamental philosophical developments of gender theory, which explores the complex problems of society and culture in the modern world; it is possible to gradually overcome patriarchal views, reductionism and populist denial of gender science and feminist philosophy.

One of the problems that cannot be overlooked when considering power and authoritarianism of any kind is the construction of value judgments about justice and reason. Lyotard addresses this issue in Just Gaming (1979), arguing that one can make value judgments without even having to rely on grand narratives (Lyotard, 1985). The principle of new narratives, which will not claim universal and imperious legitimacy, will be the "language game". It is a concept borrowed from L. Wittgenstein, which will expose the false claims of linguistic consciousness to universality. Language play is defined by Lacan as a form of symbolic action performed by each act of communication. Moreover, the rules of such a game lie in the field of social pragmatics, not semantics; they are not generally binding, and universal. Unusually important for gender philosophy is also another concept introduced by Lyotard, what he calls "event", as well as the concepts of "different" and "sublime". 
An event, according to Lyotard, is an event that drastically changes our view of the world and casts doubt on all our ideological assumptions. To recognize that there are events that cannot be predicted or captured by a "precise" universal theory is to recognize not only the limitations of "grand narratives," but also the important openness of the future. This openness becomes a matter of faith for postmodernists: the future cannot be viewed as something predetermined in advance, that all human efforts are senseless.

In Differend (1983), the scientist analyzes conflicts of interest between the parties, which cannot be resolved, but which must be recognized, and must always be considered as being (Lyotard, 1993). Each side represents what Lyotard calls a distinct "regime phrase" whose goals are incommensurable with each other, and neither

In practice, especially in political practice, it takes place that one side in a dispute or conflict forces the other to accept its point of view, thus "resolving" the conflict. And it is the task of philosophers to help such suppressed phrasal regimes find their voice, what Lyotard describes as "philosophical politics." Philosophical politics, the search for new, countercultural phrasal regimes, must be seen as the highest expression of postmodern philosophy. Resistance at the level of "small narrative" becomes an ethical act in action, and it is "discrimination" that must be defended by all means in the postmodern world.

For one people, J. Baudrillard is the highest preacher of postmodernism, who convincingly showed that "reality" is already quite different. Others believe that many important ideas have not yet been "read" in Lyotard's texts. Still others believe that the most important thing is that the postmodern world of difference enabled the oppressed to find their voice and fight against their oppression. This problem of finding your voice has a lot to do with being able to use the word "I". Nietzsche, grasping the grammatical basis of Kant's subject, criticized the belief in a coherent and whole "ego" as a product of a misused belief in grammar.

S. Freud contributed his vision to this idea, drawing attention to the conflicts between aspects of the "ego". As a result, postmodernism canonized multiple "egos", thus completing the destruction of the integral "ego" in order to a certain identity appeared that could serve as the basis for a new identity. It is these dilemmas that are very acutely felt and hotly debated in gender studies. On the one hand, philosophers such as D. Butler argue that there is no "core" identity, there is no essential "I". There is no essential category of "woman" that would serve the purpose of uniting a mass political movement. Instead, the ego and his / her gender are realized only as a performance (Butler, 1990). Others, however, support the essentialist category of woman, since if she is not there, then what comprehensible purpose does feminism serve? If we allow ourselves to move away from the essentialist reality of oppression of women, we simultaneously relieve ourselves of responsibility to real women, making feminism just an academic ploy. Since late capitalism, using the phrase of E. Mandel, popularized by F. Jason, is the main "player" of postmodernism, or post-industrial societies, as noted by many theorists and critics, the influence of its theorists like $\mathrm{K}$. Marx on gender theory is undeniable. The concept of the political unconscious, developed by Jameson, distances the author at certain strategic moments from those polemical methods that are traditionally associated with the Marxist practice of ideological analysis

According to Jameson, Marx's most significant lesson, the one that places him alongside Freud and Nietzsche as one of the greatest "negative diagnoses" of modern cultural and social life, is a lesson in erroneous consciousness, class biases and ideological programming. Behind Lyotard's violent attack on Marxism lies the belief that neither human nature nor the historical process can be predicted, and therefore controlled, as argued by the theory of Marxism.

Behind Lyotard's violent attack on Marxism lies the belief that neither human nature nor the historical process can be predicted, and therefore controlled, as argued by the theory 
of Marxism (Lyotard, 1974). Ricoeur's doctrine of meaning and positive hermeneutics had an implicitly significant impact on gender science, as well as E. Bloch's ideal of hope, M. Bakhtin's concept of the dialogical, and the Frankfurt School's concept of strong memory as a trace of reward. All these theories contain the possibility of choosing articulations in a meaning that exceeds pure ideology.

In general, symbolic fundamentalism, which became part of postmodern philosophy, provided the most important material for theoretical models of gender. Gender identity is a cultural and communicative manifestation of a person in actions; it is a representation of self through symbols of style and manner of dress, color preferences, gestures, facial expressions and gait, through the symbolic series of communication methods. Thus, as an actor, we "make" our gender identity in every interaction with society, in every situation; in this sense, gender identity is performative, since it is a representation of self in a binary opposition from the point of view of another, a signification of oneself as a socio-cultural unit of society. Performativity of gender as a philosophical concept is widely discussed and analyzed in the works of feminist scientists, and above all, J. Butler, who asserts that all gender is performative (Butler, 2011). It is important to understand that the interpretive history of gender distinction, which attempted to constitute the relationship of the gender, is itself part of the social construction of cultural reality.

\section{Conclusions}

Based on the results of the analysis, it can be concluded that postmodern discourse and its relationship with gender studies, feminist philosophy in general, is an urgent and significant philosophical problem, covering both diverse areas of human activity and various approaches to the scientific interpretation of their interconnection, mutual influence. Postmodernism offered a deep criticism of the institutions of philosophy. Postmodernists began with the development of a metaphilosophical perspective and are inextricably linked to social criticism of the subordinate position of the individual in patriarchal culture. As analysis shows, gender theory shares with postmodernism many methods of explaining and interpreting human experience (deconstruction, hermeneutics) as a way of philosophical reading of culture, which made it possible to assert that the socio-cultural dichotomy between the gender is not so much natural or biologically explicable, but arises as a result socio-cultural marginalization by power relations of certain groups of people. Historical and philosophical consideration of the formation of gender theory and its connection with the philosophy of postmodernism shows that there are a number of convergences between gender theory and postmodernism. Both the theory of postmodernism and gender science prove that the metanarratives of the Enlightenment have lost their legitimizing power, that those claims that were put forward as universal are valid only for a certain culture, class and race, and are the product of access to power but not to truth.

\section{References}

Butler, J. (1990) Gender Trouble. Routledge.

Fuko, M. (1996). Volya $k$ istine: potu storonu znaniya, vlasti i seksyalnosti. Raboty raznych let [The Will to Truth: Beyond Knowledge, Power and Sexuality]. Moskva. [in Russian]

Gellner, E. (1992). Reason and Culture. Wiley-Blackwell.

Giddens, A. (1991). The Consequences of Modernity. Stanford University Press.

Hutcheon, L. (2003). A Poetics of Postmodernism. History, Theory, Fiction. London: Routledge. 
Irigaray, L. (1977). Ce sexe qui n'est pas un. Paris: Editions de Mimeit.

Kellner, D. (1990). Jean Baudrillard: From Marxism to Postmodernism and Beyond. Stanford University Press.

Lyotard, J.-F. (1974). Economic Libidinale. Paris.

Lyotard, J.-F. (1985). Just Gaming (Theory and History of Literature). University Of Minnesota Press.

Lyotard, J.-F. (1993). Political Writings. University of Minnesota Press.

Lyotard, J.-F. (1984). Postmodern Condition: A Report on Knowledge. University of Minnesota Press.

Sim, S (Ed.) (2011). The Routledge Companion to Postmodernism. London and New York: Routledge.

Simon, J. (1987). The emergence of the risk society: insurance, law and the state. Socialist Review, 60-89.

Simon, W. (1996). Postmodern Sexualities. London: Routledge.

Simon, W., Haney, C., Buenteo, R. (1993). The postmodernization of death and dying. Symbolic Interaction. (16 (4)), 411. 